\title{
Computer - based Drug Sales and Inventory Control System and its Applications in Pharmaceutical Stores
}

\author{
*Ogwo Eme ${ }^{\mathrm{a}}$, Uchenna Ugboaja C. A. ${ }^{\mathrm{b}}$, Faustina Odinakachi Uwazuruike ${ }^{\mathrm{c}}$ and Chukwu \\ Uka Ukpai $^{\mathrm{d}}$
}

${ }^{a}$ Department of Computer Science, Akanu Ibiam Federal Polytechnic, Unwana, Nigeria.

${ }^{b}$ Department of Computer Science, Akanu Ibiam Federal Polytechnic, Unwana, Nigeria.

${ }^{c}$ Department of Computer Science, Akanu Ibiam Federal Polytechnic, Unwana, Nigeria.

${ }^{d}$ Computer Unit, Birnin Kebbi Local Government Secretariat,Kebbi, Nigeria

Received: 01 March 2017; Accepted: 11 September 2017; Published: 08 January 2018

\begin{abstract}
This paper presents a careful study and analysis of an existing manual sales and inventory control system of a pharmaceutical store and aimed at designing and developing a computer-based system in order to increase the efficiency and accuracy of the business operations of the pharmaceutical store. The study was carried out to reduce the problems of inconsistency and inaccuracy of sales and drug data inherent in the existing manual system of the pharmacy. An analysis of the current manual system was done to get a better understanding of the system. The Rapid Application Development (RAD) methodology was used in this work to implement an iterative program which is suitable for stand-alone applications that can be updated from time to time as may be required by the computer -based system. Testing was done in every phase of the development life cycle to ensure that the new system works properly. The software was developed and implemented using Visual Basic 6.0 programming language and Microsoft Access for the database platform. The software developed provides alert of every expired drug and minimum quantity of each drug available in stock. Other activities such as product sales, drugs and users registration, and periodic reports generation can also be carried out with the new system.
\end{abstract}

Index Terms - Computer-based, Control, Drugs, Inventory, Pharmacy, Sales, Stock.

(C) 2018 Published by MECS Publisher. Selection and/or peer review under responsibility of the Research Association of Modern Education and Computer Science.

\footnotetext{
* Corresponding author.

E-mail address: ogwoeme@yahoo.com
} 


\section{Introduction}

In the earliest days of drug store keeping, pharmacists wrote down purchases of drugs or they looked at how many units were gone at the day's end and then did their best to forecast future needs. Experience and intuition were the key skills but remained an inexact method, even when applied to operations that were quite small by today's standards.

Pharmacists know they needed a better system and in the 1960s, researchers created the forerunner of the modern bar-coding system which used ultraviolent light sensitive ink and a reader to mark items for sale. During the mid to late $1990 \mathrm{~s}$, retailers began implementing modern inventory management systems, made possible in large part by advances in computers and software technology. The system work in a circular process, from purchase tracking to inventory monitoring to re-ordering and back again. The technology evolved into a comprehensive inventory management solution by the early 2000s. And even small and medium size businesses can find affordable inventory management software to meet their business needs.

A sales system is set of principles, business strategy and tools that are designed to help business organizations manage and track their sales deals, more efficiently, effectively and accurately.

Inventory basically is the total amount of goods and materials held in stock by a factory, store and other businesses. An inventory system is a process whereby a business keeps track of the goods and materials it has available. In its simplest sense, it can be done manually by a count at the end of each daily activity. In this way, it is possible to keep record of the goods coming into the business and goods being sold. Therefore, drug sales and inventory control system is a system designed to manage the daily sales activities and keeping track of the available drugs in a drug store or pharmacy.

Since manual inventory takes a lot of time and is prone to errors, it will be helpful to build a system that will computerize the transactions from the point of acquisition of the product description to updating the inventory database. The proposed drug sales and inventory control system will improve employees' work efficiency by computerizing routinely and time consuming tasks such as the time spent in taking down drug's information. As a result, the time can be used in more productive activities. The accuracy of the current system will also be improved, since the computerized drug sales and inventory control system will eliminate the need of constantly encoding lengthy details of products by having an inventory database. Monitoring encompasses the tracking of individual process, so that information on their own state can be easily seen and statistics on the performance of one or more process can be provided.

\section{Statement of the Problem}

The existing manual sales and inventory control system used by many pharmaceutical stores has been discovered to suffer the following setbacks:

(a) The manual tasks in the system cause delay in processing of sales records and these result to untimely generation of information for management's decision making.

(b) The existing manual system suffers inconsistency and inaccuracy of information generation from the business activities of the pharmacy.

(c) Break down of supply always occur as a result of inability of the pharmacy management to prepare reliable records in order to know when to re-order for new drugs and there are no alert messages to remind for critical minimum quantity or low stock level of each drugs and their expired date.

(d) Updating of the sales and inventory records takes more time than necessary since transaction records are allowed to accumulate before they are being processed and there is no automated processes in data manipulations such as add, insert, delete, update and searching. Also, location and accessibility of drugs in the shelf among staff of the pharmacy takes longer than necessary. 


\section{Objectives of the Study}

This study was carried out in order to computerize the existing manual sales and inventory system of pharmaceutical stores, thereby helping in timely generation of information for effective decision making of the pharmacy management. The proposed system is also aimed at solving the problem of inefficiency and inaccuracy of the existing pharmacy's manual system by preventing data entry errors, helps the pharmacy management to adequately control the flow of drugs in the pharmacy store to minimize the risk of being under stocked which could disrupt the business activities of the pharmacy leading to customers dissatisfaction.

Moreover, the proposed drug sales and inventory system is aimed in ensuring total accountability of the business activities of pharmaceutical stores and restrict access to unauthorized users from gaining access to the system information.

\section{Significance and Scope of the Study}

\subsection{Significance of the Study}

This study will enable the staff and management of pharmaceutical stores currently using manual drugs sales and control system to feel the impact of a computerized business management system such as the proposed computerized drug sales and inventory control system. Through this study, other pharmacies and business operators will come to understand and realize the importance of computerized business management systems and may wish to join the computerization trend.

This work will also help to minimize the unintentional purchases and intake of expired drugs (caused by the current manual system) by individuals and members of the society who buy drugs from pharmacies and also encourage other pharmacies to join the computerization trend, thereby reducing the rate of intake of expired drugs by individual members of the society leading to death of the victim or may cause serious health related problems as a result of the intake.

\subsection{Scope of Study}

This work is a stand-alone system, developed and runs on windows operating system platform. It focuses on computerization of an existing manual drug sales and inventory control activities of a pharmacy. This computerization is aimed at reducing data discrepancies and errors that frequently arise from the current pharmacy's business operations and also lessen the work of the authorized personnel of the pharmacy with respect to sales operations and tracking of the pharmacy's stock record using the current system. Hence, the proposed computer - based system is limited to the sales operations and tracking of stock records of the pharmacy's drug inventory.

\section{Related Works}

In order to obtain data that will be beneficial to the study objectives, background information was obtained for more knowledgeable and precise understanding of the topic. This section deals with combination of summaries of various related literature and is divided into sub-sections which include: Inventory control in pharmaceutical stores, the role of information and communication technology (ICT) in the inventory control system of pharmaceutical stores, benefits of computerized drug sales and inventory control systems, effects of computerized sales and inventory control systems on customer service delivery, effects of non-implementation of computerized sales and inventory control systems in pharmaceutical stores. 


\subsection{Inventory Control in Pharmaceutical Stores}

Reference [1], defined inventory control as an activity employed in maintaining the optimum number or amount of each stock item or is defined as the activity of checking a shop's stock. It defined Inventory control system as a system that encompasses all aspect of managing a company's inventories: purchasing, shipping, receiving, tracking, warehousing and storage, turnover and re-ordering.

Reference [2], stated that inventory control in pharmacy operations is referred to the stock of pharmaceutical products retailed to meet future demands. He further stated that inventory represents the largest current asset as well as liquid asset in pharmacy practice and its value continues to rise because of the growth in variety and cost of pharmaceutical products.

\subsection{The Role of Information and Communication Technology (ICT) in Inventory Control System of Pharmaceutical Stores}

As electronic computers become more common and affordable, manual method of inventory control became less practical.

Reference [3], observed that barcodes system accelerate the flow of products and information throughout an enterprise and offers effective electronic Inventory Systems on Customer Service Delivery in selected Supermarkets in Kenya. The most familiar examples of this, is the Electronic Point-Of-Sale (EPOS), which is commonly used in supermarkets where sales are recorded by scanning a product's barcode at the checkout points. Computerization has revolutionized inventory management as technologies ranging from automatic scanners to radio frequency identification chips now allow businesses to track their inventory from the moment the products leave the building to the hands of customers [4].

In today's business environment, even small and medium scale businesses have come to rely on computerized inventory management system. Certainly, there are many of smaller retail outlets, manufacturers and other businesses that continue to rely on manual means of sales and inventory tracking. The recent development of powerful computer programs capable of addressing a wide variety of record-keeping needs, including sales and inventory management in one integrated system have also contributed to the growing popularity of electronic inventory control options. Therefore, it is very important to determine the level of the integration required between the inventory control solution and existing information systems [5]. Reference[6] indicated that manufacturers are increasingly dependent on the benefits brought about by information technology to: improve supply chain agility, reduce circle time, achieve higher efficiency and deliver products to customers in a timely manner. The decision to store information and communication technology within the inventory control could encourage the commitment of establishing relational behavior [7]. Inventory management is an approach which is being viewed by organizations and companies in many sectors as a key source of competitive advantage. Reference[8], defined inventory management and outlined the role of ICT as a key enabler of the process. According to reference [9], the application of ICT, both within and between organizations provides opportunities for improvement in the data storage, analysis and communication in many areas of procurement activities including drugs procurement. The increased speed of transmission of data can shorten lead-times and bring about improvement in the synchronization of activities at different points of an organization's business locations.

The inventory control and purchasing policies were of utmost importance among pharmacy management functions performed as they had great impact on the pharmacy. Sound purchasing and inventory control go hand in hand and their effectiveness depends upon each other.ICT can improve inventory management in pharmaceutical stores. ICT facilitates easy communication of stock-outs by customer facilities to the suppliers or notification of stock-outs by suppliers to their customers. The intranet and extranet technologies, and inventory system can be linked directly to the suppliers so that it automatically places orders for products when stock on hand falls below a certain level $[10,11]$ 


\subsection{Benefits of Computerized Drug Sales and Inventory Control Systems}

Reference [12], opined that the use of technology is for those who seek to improve the overall efficiency of an organization using inventory control options. An advantage of such system is that it will allow faster and more efficient delivery especially of prescription drugs to the patient(s). However, in another article [13], it was also stated that this computerized drugs dispensing system was the most suitable work flow system and prescription processing that provides an advantage. It was further mentioned that, there are six(6) critical features of the system (which are: smooth workflow process, integration capabilities, centralized view of data, work load balancing, record of counseling activities and integration across channels), and that, all contribute to a functionally driven pharmacy. Information technology was stated as being an important and crucial part as well, not only for proper functioning of the pharmacy but also for inventory control.

\subsection{Effects of Computerized Sales and Inventory Control Systems on Customer Service Delivery}

Reference [14], described customer service as the fulfillment of customers' orders effectively and efficiently and at the minimum cost. According to him, customer service delivery involves meeting customers' expectations with respect to order fulfillment through shorter lead-times, consistent and on time delivery, complete orders, quicker response to customers' requirements and the ability to meet unique and special requests of the customer. The author noted that computerized sales and inventory control systems assist in quicker order processing and have led to improved customer satisfaction through quicker and more accurate responses to customers' requests. He concluded that, with electronic inventory control systems, it takes only a few key strokes to answer customer's inquiry. The use of electronic inventory control system looks for ways of increasing flexibility by moving to smaller and frequent deliveries with shorter lead-times and flexibility reduces lead-time and ensures that specific customers' requirements are met [15]. Information sharing through the use of electronic inventory control system enables the chain partners to compress lead-times and know how much they should have in stocks to meet customers' demands and also, these stocks enable chain partners to provide deliveries on time to their customers [16].

\subsection{Effects of Non-Implementation of Computerized Sales and Inventory Control Systems In Pharmaceutical Stores}

The disastrous effects that would occur with improper or chaotic and manual inventory management were highlighted. According to reference[17], examples of such management include; high level of unnecessary inventory when sales forecast were not in line with actual transactions, no periodic review of inventory and distribution process, safety stocks maintained were more than necessary and manual checking as opposed to automated checking resulted in human errors, all of which contributed to inaccuracy of inventory reports. According to [17], from the statistics of ten (10) pharmaceutical companies where five(5) of the companies' inventory control is manual and the remaining 5 were computerized, it was observed that, at present, manual system loss in inventory management is now $8.9 \%$ over computerized inventory management. According to him, the main causes for this manual inventory control loss are - wrong order taking, theft of products, wrong information about the inventory, erroneous money collection from customers, under-billing etc. due to the paper-based work.

\subsection{Intelligent systems for disease diagnosis}

According to reference [18], computer programs are applied in the computation time; computation cost in treatment of diabetes diseases and in maximizing the accuracy and better diagnosis of diabetes diseases. The authors used a methodology in their work. The methodology was implemented in 2 stages: (a) in the first stage 
Genetic Algorithm (GA) has been used as a feature selection on Pima Indian Diabetes Dataset. (b) In the second stage, Multilayer Perceptron Neural Network (MLP NN) has been used for the classification on the selected feature. GA is noted to reduce not only the cost and computation time of the diagnostic process, but the proposed approach also improved the accuracy of classification. Reference [19] used a genetic algorithm (GA)-based features selection to improve the accuracy of medical data classification. The proposed genetic algorithm-based feature selection removes the irrelevant features and selects the relevant features from original dataset in order to improve the performance of the classifiers in terms of time to build the model, reduced dimension and increased accuracy. The authors implemented the method using MATLAB and tested using the medical dataset with various classifiers.

\section{Program Design Methodology}

The design and implementation of a computer -based Sales and Inventory Control System plays a very important role in the health of members of the society especially people living in the vicinity where the Pharmacy is sited. A Program Design Methodology or system development methodology in software engineering is a framework that is used to structure, plan and control the process of developing an information system. Some of the methodologies are: Agile Software Development, Crystal Methods, Rapid Application Development (RAD), Spiral Model, and Waterfall Model.

The design methodology adopted in the design and development of the proposed system is Rapid Application Development (RAD) model. Rapid Application Development model is one of the software development methodologies which make use of minimal planning in favor of rapid prototyping. In RAD model, the functional modules are developed in parallel as prototypes and are integrated to make the complete product for faster product delivery. Since there is no detailed planning, it makes it easier to incorporate the changes within the development process.RAD model enables rapid delivery as it reduces the overall development time due to reusability of components and parallel development. It puts less emphasis on planning tasks and more emphasis on development which is in contrast to the waterfall model of Software Development Life Cycle (SDLC) that emphasizes on rigorous specification and planning.

The new computerized system has been developed to replace the existing manual system thereby reducing the time it takes to calculate and store data. The new system is strong enough to withstand regressive daily business operations under conditions where the program's database is maintained and cleared over a certain time of span. The implementation of the new system in pharmaceutical stores is deemed to considerably reduce data entry errors, reduce data processing and also provide readily calculated reports. There is always a room for improvement in any software no matter how efficient the system may be. The important thing is that the system should be flexible enough for future modifications. The new system therefore, has been factored into different modules for easy maintenance operations. Every efforts has been made to cover all users requirements and making the new system to be user friendly.

For the purpose of choosing a progamming language which will be suitable and available for the development of the proposed system, the authors selected Visual Basic as the programming language (Frontend) and Microsoft Access as the database platform (Back-End) Microsoft Access was chosen as the program back-end because of its relational database structure and its ability of connecting and be manipulated using Visual Basic Program applications. Hence the Computer -based Sales Drugs and Inventory Control System for the pharmaceutical store was developed and implemented using the programming tools stated above.

\section{Application Details and Program Output}

\subsection{Application Details}

The application details explain how the developed computerized program is implemented in order to achieved it's set objectives. Below are the application details of the new system with respect to its 
functionalities and operations/tasks which both ordinary users and the administrators of the system can perform with it.

(a) Launching or Starting the Program:To launch the program on a computer after installation, operators are expected to follow these traditional steps of launching programs.

- Click on "Start button"

- On the Start menu, select and click on "All Programs"

- On the All Programs menu, select and click the applications name(NGH-PHARMACY-MANAGER) to launch the application on the computer system.

(b) The New System Login Procedures:The new system shows a startup screen when launched and finally displays the program's main menu. There are only two logon options on the main menu which are Administrator's Login and Staff/Users Login options.

To login to the system using any of the login options, the following steps are taken:

- Select and click on any of the login options at the left hand pane of the program's main menu.

- Enter your login credentials (Username and Password)

- Finally, Click on the Login Button or Click "Cancel button" to cancel login

This section is where all sub programs that will run on the main program modules are being specified. Below are the sub program modules with their explanation:

The Administrator's Subroutine: Below are some of the tasks available in the administrator's module.

(a) New Staff/Users Registration: Thistask involves addingNew and old employees of the pharmacy into the new system to become users of the system bygiven them right to have access to the new system through the provision of unique login username and password for them by the system administrator

(b) Inventory Control Tasks: These involve the processes of adding new products into the new system, stock monitoring, updating re-ordered products' stock information, deletion of expired products from the system and other stock control related tasks.

(c) Product Sales Task: This task can be performed in both the administrator's subroutine and in users' subroutine. It involves selling of products and generating sales invoices for every performed transaction in the new system.

(d) Report Genration Tasks: This involves generating reports such as daily, monthly and yearly sales reports and stock balance reports from the new system. Here, data will be available to know about the products sold in daily, monthly or yearly. These reports can be used for future references.

The Staff/User Subroutine: Program tasks in this subroutine include the following described below:

(a) Product Sales Task: This program task is available for the users of the new system to sell pharmaceutical products to customers, generate invoices and sales reports as well as printing the generated reports.

(b) Stock Control Tasks: Here involves only checking, viewing and printing of stock reports.

\subsection{Program Output}

This newly developed software was demonstrated in a pharmacy - New Good Health Pharmacy Ltd, ,Afikpo, Nigeria in order to eliminate the problems which are inherent in the existing manual system and also aimed at 
solving the challenges of inefficiency and inaccuracy of the existing pharmacy's manual system by preventing data entry errors, helps the pharmacy management to adequately control the flow of drugs in the pharmacy store in order to minimize the risk of being under stocked which could disrupt the business activities of the pharmacy leading to customers dissatisfaction. The developed computer -based system achieved the following functions: Drugs and users' registration, stock balance calculations, issuance of alerts on every expired drug and low stock items, generation of business reports etc. Some of the sample windows of the Computer- based Drugs Sales and Inventory Control System for New Good Health Pharmacy Ltd, Afikpo, Nigeria are shown below:

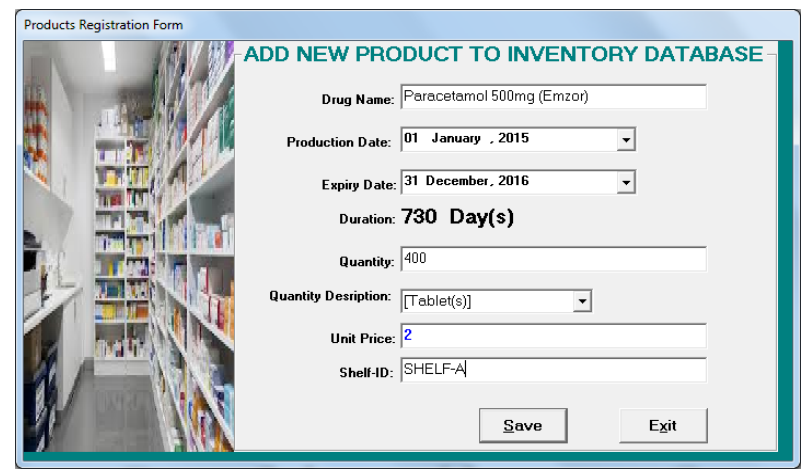

Fig.1. Products Registration Inventory form

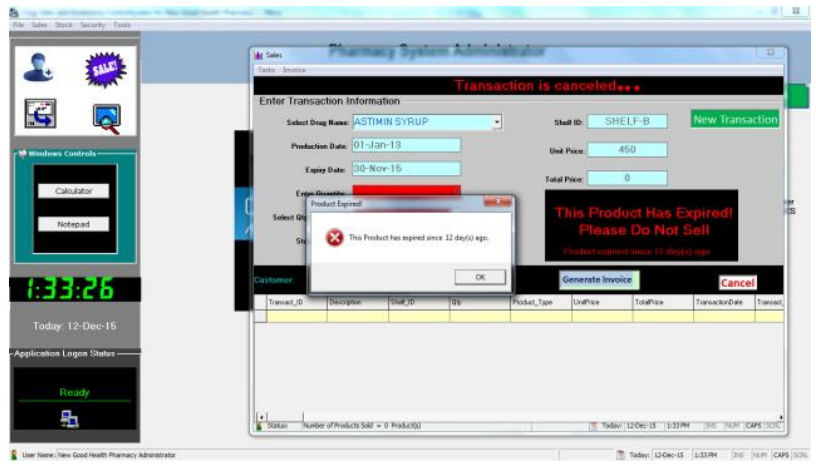

Fig.2. Expired Products Tracking Window

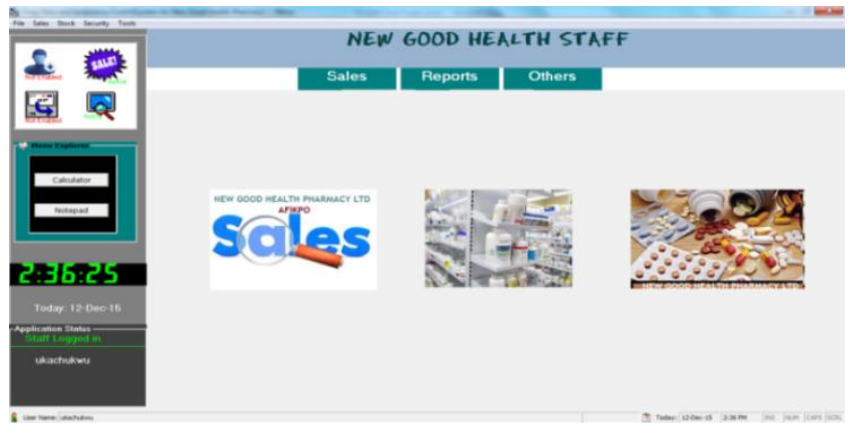

Fig.3. Product Sales Window 


\section{Conclusion}

This work has enabled the authors to design a computer - based drug sales and inventory control system to ascertain stock levels of all the inventory products, keep status and updates of all business transactions in a pharmacy hereby helping in managerial decisions, progress level and effective stock taking in the pharmacy.

The results of this work showed that for effective and efficient use of a computer - based drug sales and inventory control system and other software applications, an intuitive and flexible user interface plays an important role. It should also be noted that a good inventory control system is a backbone of any retail operation and therefore, proper and good design of a computer -based inventory system offers great achievement, increases more operational efficiency and effective usability of the system by its users.

This work have proved that in order to reduce the sale and use of expired pharmaceutical products in the society, drug sales and inventory control systems should be programmed to issue proper alerts of every expired products in the inventory system's and also disable every command that will enable the sale of such expired pharmaceutical products to the general public or a customer by the users of the system.

\section{References}

[1] Web Finance, "The Business Dictionary", 2016.

[2] Surabhi, R. and Suen, O, "Inventory Management: A tool of identifying Items that Need Greater Attention for Control". A Journal of Inventory Control and Management, Toronto. Vol. 1. pp. 45-51, 2012.

[3] Mugo, R. "Effectiveness of Electronic Inventory Systems on Customer Service Delivery in selected Supermarkets in Kenya."European Journal of Business and Management.25(2), 32-38,2014.

[4] Ellis, D, "The Uses of Computer in Inventory Control". New York University: Elsevier Inc, 2012.

[5] National Community Pharmacists Association (Managing the Pharmacy Inventor: .An annual Report, 2010.

[6] Fasanghari, M., Farzard H.R., and Kamal,S.C, "Assessing the Impact of Information Technology on Supply Chain Management, Word Applied Science Journal 4(1): 87 - 93,2008.

[7] Grover, V., Teng, J and Fiddler,K," Investigating the Role of Information Technology in Building BuyerSupper Relationships, J. Association Information Systems 3: 217 -245, 2002.

[8] Sweeney, E, "Managing the Supply Chain: The Role of Communication and Information Technonolgy (ICT) as a Key Enabler of the Process", Business Ireland, Summer Issue pp 105 -109, June, 2005.

[9] Sauders, S, "Impacts of ICT in Inventory Control" Nairobi: Acts Press, pp. 73-81, 1997.

[10] Blackburn, J, "Fundamentals of Purchasing and Inventory Control for Certified Pharmacy Technicians": A Knowledge Based Course. New York: Greenwood, (2010).

[11] Dunning, W. D, "Service Management, Operations, Strategy and Information Technology, 2nd Edition (pp. 262 - 295).New York, NY: Irwin McGraw-Hill, (2007).

[12] Draper, L, "Computerized Dispensing System", The New York Times, (2010).

[13] Damle, K., and Puri, K., "The Right Pharmacy Management System" .E- Journal of Pharmacy Management, 28(2), 6-9, (2010).

[14] Chopra, S, "Supply Chain Management”, 2(2).pp 33- 41, 2004.

[15] Waters, D, “Operations Management, 2nd Edition" Harlow: Pearson Education, (pp. 48-52). 2002.

[16] Keong, C., Ahmad, M., Sulaiman, N. and Ismail, M, "Proposing a Non-traditional Ordering Methodology in Achieving Optimal Flexibility with Minimal Inventory Risk" .Journal of Marketing and Logistics Vol.17 pp. 31-4, 2005.

[17] Paul, D. and Ravichandran, K., "Best Practice Management in Inventory Control" London: D.P $\begin{array}{lllll}\text { Publications } & \text { Ltd, } & \text { (pp. } & 192 & -\end{array}$

[18] Dilip Kumar Choubey, Sanchita Paul, "GA_MLP NN: A Hybrid Intelligent System for Diabetes Disease Diagnosis", International Journal of Intelligent Systems and Applications (IJISA), Vol.8, No.1, pp.49-59, 2016. DOI: $10.5815 /$ ijisa.2016.01.06 
[19] D. Asir Antony Gnana Singh, E. Jebamalar Leavline, R. Priyanka, P. Padma Priya,"Dimensionality Reduction using Genetic Algorithm for Improving Accuracy in Medical Diagnosis", International Journal of Intelligent Systems and Applications(IJISA), Vol.8, No.1, pp.67-73, 2016. DOI: 10.5815/ijisa.2016.01.08

\section{Authors' Profiles}

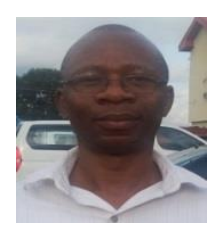

Ogwo Eme is currently a lecturer at the department of Computer Science, Akanu Ibiam Federal Polytechnic, Unwana, Nigeria. His teaching interests include Database Design and Management, Project Management, Information Technology, Computations and Modelling e.t.c. He conducts research majorly in Computer Science and Computer Education. He holds A Bachelor of Science (B.Sc) degree in Computer Science in 2004 from Michael Okpara University of Agriculture, Umudike, Nigeria, Master of Science (M.S.c)degree in Computer Science in 2011 from Imo State University, Owerri, Nigeria and a Post Graduate Diploma in Education in 2013 from Usman Dan-Fodio University, Sokoto, Nigeria. He is a member of Computer Professionals Registration Council of Nigeria and Teachers Registration Council of Nigeria. (TRCN).

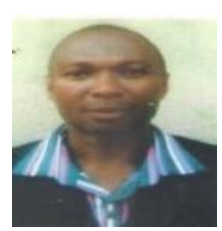

Uchenna Ugboaja.C.A. is currently a lecturer at the department of Computer Science, Akanu Ibiam Federal Polytechnic, Unwana, Nigeria. He is a seasoned System Analyst with outstanding industrial experience. His teaching interests include: Software Engineering, Database Systems and Computer Networking. He is a graduate of Computer Science. He holds a B.Sc degree in Computer Science from the Institute of Management and Technology (IMT),Enugu, Nigeria.. He also holds PGD and Master of Science (M.Sc) degree in Computer Science from Federal University of Technology, Owerri, Nigeria and Ebonyi State University Abakaliki, Nigeria respectively. He is a member of professional bodies such as Nigeria Computer Society, Computer Professionals Registration Council of Nigeria and British Computer Society.

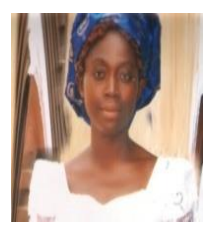

Faustina Odinakachi Uwazuruike is currently a lecturer at the department of Computer Science, Akanu Ibiam Federal Polytechnic, Unwana, Nigeria. Her research interests include Software Engineering, Database System and Computer Applications. She holds a Higher National Diploma (HND) certificate in Computer Science from the Akanu Ibiam Federal Polytechnic, Unwana, Nigeria.

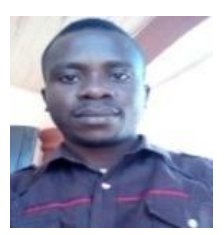

Chukwu Uka Ukpai is currently a freelance Computer Analyst. His interests include Software Development and Computer Networking. He holds a Higher National Diploma (HND) certificate in Computer Science, from Akanu Ibiam Federal Polytechnic, Unwana, Nigeria.

How to cite this paper: Ogwo Eme, Uchenna Ugboaja C. A., Faustina Odinakachi Uwazuruike, Chukwu Uka Ukpai,"Computer - based Drug Sales and Inventory Control System and its Applications in Pharmaceutical Stores", International Journal of Education and Management Engineering(IJEME), Vol.8, No.1, pp.30-39, 2018.DOI: 10.5815/ijeme.2018.01.04 